\title{
Women and New Information Technologies in the Public Broadcasting Domain: Television Commercials
}

Lequn $\mathrm{Fu}$

School of Communication, City College, Zhejiang University

\begin{abstract}
The paper reviews the current thinking about the relationship between wo men and information technology and gender roles in television commercials, and then explains how the gender roles of women in television commercials reflect feminist th eories. Suggestions are provided to address the problems mentioned. It concludes that information technology is a way of advocating for and consolidating masculinity. In a ddition, it builds female stereotypes and expands the distinction between men and wo men.

KeyWords. Women; New Information Technologies; Public Broadcasting; Televisio n Commercials
\end{abstract}

\section{Introduction}

Men and women have different relationships with information technology; women are usually portrayed as less adept or familiar with it. Portrayals of women and men in American television commercials shape popular notions of femininity and masculinity and influence audiences. To a certain degree, advertisements reflect social and cultural beliefs about gender and its relationship to information technology. As McMahan (2008) noted, an identity is easily transmitted via a slogan, media, or pictures. The relationship between women and information technology is reinforced by advertisements and is considered to be related to the domestic use of information technology rather than its production. In addition, women and girls have few opportunities to subvert their stereotyped roles through American commercials; in consequence, to some extent, information technology consolidates masculine influences. In addition, information technology shapes notions of femininity and masculinity and, thereby, reinforces gender stereotypes. I will first review the current thinking about the relationship between women and information technology and also gender roles in television commercials, and then I will explain how the gender roles of women in television commercials reflect some feminist theories. I will also provide suggestions for ways in which to address this problem. I will conclude that information technology is a way of advocating for and consolidating masculinity. In addition, it builds female stereotypes and, thereby, expands the distinction between men and women.

\section{The role of women and information technology in American Television Commercials}

In both the public and private domains, women usually play a stereotypically gendered role and are treated unequally compared to men, especially in American television commercials, in which 
women are often portrayed as being without occupation and both economically and psychologically reliant on men. In an advertisement for the Frigidaire Automatic Spray Tube Dishwasher, the main character is a "mom" and "housewife" who spends all of her time taking care of household duties and children. Different relationships between gender and information technology are also presented and reinforced by information technology (commercial advertisements). For instance, men build a building and women live in it, men design a dishwasher and women use it, women take flight and men fix it, etc. Information technology always presents women's exterior appearance and bases its value-judgments on this. Many commercials use women's exposed bodies to appeal to men and to describe and value women only insofar as they relate to sex. Women are not socially recognizable in terms of technology; this is what we call a "stereotype."

Information technology shapes masculinity and femininity and, to some extent, reinforces the stereotypical gender roles of men and women. The stereotypical role of women usually is portrayed as a subordinate role to men with an inferior position in regard to interaction with information technology. To a certain degree, stereotypical gender roles represent the fact of gender inequality and reflect social values and cultural beliefs. It is not hard to find stereotypical gender roles used in many commercial advertisements. As Demiray (2010) argues, "New information technologies are mostly at the level of passive use and consumption for women" (p. 4). This is means that information technology could be an efficient way of advocating and consolidating masculinity and, thereby, prevent the emancipation of women. Therefore, men and women have different relationships with information technology; women are always portrayed as the passive users of information technology, rather than the dominant producers.

Labor activity is a production activity that relates to food, clothes, residence, or some other aspect of daily living. As the establishment of patriarchy, human society has been divided into two spaces, public and private. The differentiation of public and private life build the social concept that women are inferior to men, i.e., that men are breadwinners and women homemakers. Under a patriarchal system, women become the private property of men, which, of course, devalues women themselves. The traditional gender division of labor represents obvious gender differences in society, emphasizing the gender hierarchy and sexual isolation in the field of social labor.

Information technology demonstrates and controls the hierarchical relationship between men and women. It continually subvert women's confidence to dominate information technology and also reinforces women's attachment to men. As Demiray (2010) argues, it is hard for women to be dominant, because, in the world of information technology, women usually are usually considered to be technology-illiterate. In addition, patriarchal culture dominates information technology. Women are always seen as "far away" from technology, and men are regarded as "technology people." In an example of an Hewlett-Packard advertisement, "HP: Make it Matter" and a television commercial for the car manufacturer Audi, women are portrayed as the user of an HP laptop and the passenger of an Audi automobile. Men in these two advertisements are portrayed as engineers, the creators of the car, and are connected with or shown with scientific pictures and icons. Engineering culture presents technology as masculine. Additionally, characteristics that relate to labor and machines are also portrayed as "masculine": dirty, noisy, and dangerous. Information technology plays an important role in building that stereotyped role for women and expanding the distinction between men and women, because the ideology that most information technologies are used to present is negative and narrow in view. As a result, it indirectly reflect the patriarchal values in information technology.

\section{Patriarchy and Technology}

Heidi Hartmann (1976) regards patriarchy as the social relationship based on material status; the hierarchical relationship between men and men and their material worth leads to the control of women. In addition, many researchers claim that the oppressed situation of women can be defined as a phenomenon of ideology, culture, and psychology. In our daily life, patriarchy exists in a 
variety of fields. Demiray (2010) points out that every step of the development of technology (design, production, etc.) is performed by men; women, generally, are excluded. As the feminist researcher Ursula M. Franklin (1999) claims, technology is a kind of system in a specific culture, society, and therefore reflects societal structures. Therefore, technology is being regarded as a tool for men to oppress women, no matter if it is in the context of technology production or family life. Changing deep-rooted patriarchy is important. Hartmann (1976) says that patriarchy and capitalism interact with each other and also utilize the system of gender division of labor to make family align with society. This, as a result, leads to an unequal relationship between men and women. Therefore, if women want to have an equal social position with men, it is necessary to eliminate the gender hierarchy in the division of labor and allow men and women to have the same opportunities to get access to work. Another famous feminist scholar, Sandra Harding (1986), argues that, in a patriarchal society, technology inevitably reflects the social policies and ideological bias of the dominant male group's racism, classism, or sexism. Thus, in order to use technology to promote the development of women, the first thing that must be changed is the dominance of patriarchy.

The mutual shaping of gender highlights the relationship between gender and technology. Technology not only constructs the origin of social gender-relationships, but also constructs the result. Wajcman (1991) argues that technology is a product of culture that is constructed by specific knowledge, social practice, and even other symbolic forms. Technology also is a product of social material, which contains technology, human beings, cultural meaning, and knowledge. The interest of social gender and social gender identity is the most important aspect in the relationship between technology and social shaping. According to S. Harding, social gender symbolization is related to the gender metaphor of dualism, the structure of social gender based on social activity, and regime and gender hierarchy from the dualism system. Individual social gender means personal identity that is not related to social construction and gender differences.

\section{Technology and Family}

The initial purpose of many family technologies was not family use; they existed for business, industrial, or even military purposes. Feminists claims that the "family revolution" did not reduce or eliminate household work. Mechanization brings more new work, even though this work doesn't necessarily involve heavy physical labor; however, it requires a similar time commitment to using previous technologies. While family technology improves the efficiency of work, it also changes social perceptions of the role of housewife, creating more housework for them. Thus, the users of family technology (dishwasher, microwave, etc.) are the independent and virtuous women. Technology hasn't emancipated women from family; on the contrary, it has further entrenched them in the social organization of gender.

New information technology could provide opportunities for changing the gender division of labor, but it is the "technology" of social gender-relationships; women cannot receive the right of capital, right to education, and the practice experiences that technology relies on. As a result, the traditional gender division of labor still remain stable in the new industry era. On the other hand, employers tend to do research and development and, thereby, choose women who are benefiting for low-paid and low-coalition instead of high-paid and high-coalition's male labor forces, as the velocity of technology renovation will be influenced by different labor prices between these two genders. In the household field, the development of household technology affects the household work and gender division of labor. In addition, women, as the users of household technology, reconstruct it. Because in the 20th century, the household appliances hadn't reduced the time spent by women in the household and also hadn't changed the traditional division of labor at home. On the contrary, most household technologies are designed by men, and the result is not always just challenge, but consolidation of the mode of household work. Women function not just as passive consumers; they participate in the reconstruction of technology's connotations and function. For 
instance, the history of the microwave being transferred from military products to male leisure products to household use denotes reconstruction and occupation from women users.

Technology is full of bias, and the bias labels women as inferior. Technology is designed by men; women can use technology, but they cannot understand it. When women begin to use those technologies (dishwasher, dryer, and washing machine) created by men, they may already under men's control. Thus, technology can be considered as patriarchy and a form of hegemonic masculinity. As Susan Ormrod and Cynthia Cockburn's research on the microwave oven shows, this technology is quite similar to other technology designed by men and used by women. Women's experiences in the development of the microwave play a decisive role; some women somehow think that they are meaningfully engaging in engineering or scientific jobs, but a person who subscribes to the patriarchal-technology culture has the opposite opinion. Technology's gender characteristics are not only illustrated in technology design and production, but also in the market, use, and in other pathways that feed back to technology. In addition, the market and consumers are all in the constant process of shaping technology. These opinions demonstrate that women anticipate progress of in the field of technology and, also, that women could construct technology to their own benefit.

\section{Information Technology and Women}

Information technology changes the labor division mode. As Wajcman (2004) argues, "women have very limited access to scientific and technical institutions and careers." Mass media, schooling, and even parenting all transmit the idea that women are not suitable or smart enough to obtain access to technical jobs. To some extent, these social values transmit and consolidate masculinity. The development of information technology has not diminished the unequal relationship between men and women. As Zoonen (2001) notes, information technology has changed the traditional gendered labor division mode from centralization, upsizing, and standardization to decentralization, miniaturization, and individuation. In the field of information technology, females are nearly always portrayed as the consumers because of their comparatively low cultural quality and insufficient economic capacity.

In the 1980 s, many feminists began to investigate the development of technology and the process of technology use. In addition, they studied gender division of labor affects this process. Marx's analysis on the relationship between capital and labor shows that capitalism chases the profits by constantly adopting new technology and, thereby, making labor easy to control. However, some feminists argue that Marxism overlooks the gender of labor division through control of the labor. They believe that division of labor is a an institutor of gender hierarchy when it is based on paid labor as its primary characteristic. Gender division of labor constructs the production relationship of capitalism together with division of hierarchy. Based on Wajcman's (2004) analysis, one of the most essential ways for gender division of labor to interact with technology change is the price of labor. The labor cost of women is normally lower than men's, and it influences technology change. In the 19th century, the textile industry barely progressed, technologically speaking, because women constituted the majority of the textile labor force; since the labor force was cheaper, there was no motive for technology improvement.

Concerning the question of gender value in science and technology, Lewis Mumford (1970) provides some investigation. He recognizes the effect of women's visualization and imagination in the early period of technology progress. When technology and the machine-progress era came up, the element of women nearly totally disappeared in the field of technology. As Mumford argues, modern technology's rational and objective characteristics and women's values (subjectivity, intuition, and irrationality) is able to play an important role in technology progress and also important for the progress of life-oriented technology.

As Demiray (2010) notes, media plays an essential role in shaping gender roles and transmitting stereotypes. The role of "mother" is one of the most popular depictions of women in advertising. For example, in the dishwashing commercial advertisement from Frigidaire for the 
Frigidaire automatic Spray Tube Dishwasher, a woman says "my business doesn't begin until the party ends." The "mother" is portrayed as the person who has the most direct relationship with the dishwasher, and her mode of dress also cements her identity as a housewife and user of technology. In the commercial, she notes: " the dishwasher got my back." She organizes a birthday party, take care of her children, and so on. In this advertisement, there no male character appears, thereby enforcing the relationship between the dishwasher and women. As McMahan (2008) claims, advertising reflects social and cultural values with regards to gender and also affects individual social beliefs through its textual and visual messages.

\section{Technology and Society}

Technological determinism is one of the most influential theories about the relationship between technology and society. The central argument of this theory is that it considers technology as inherently independent and assertive; it is a power that human beings cannot necessarily control. On the contrary, social values and structures are highly influenced and decided by technology. Technological determinism is one of the most influential theories regarding the relationship between technology and society. As Wajcman (2004) claims, this theory can be divided into two parts; first, technology as an independent system from society and, second, technology influencing the society in a one-way, linear manner. Technology change is not influenced by human society, and the invention of technology cannot force the society to use technology, but society plays an important role in choosing and using technology.

Radical feminism argues that patriarchy is the primary source of the oppression of women. Women and men are usually regarded as different, and men always control or dominate women's lives, culture, or jobs. Information technology continues to promote the stereotypical gender role of women and, indirectly, influences society. Radical feminism has considered technology deeply: it is clear that technology is highly controlled by men , and gender/ power relationships are highly involved with it. As Wajcman (2010) argues, women gradually become the victims of patriarchal technoscience. The solution for this social problem is to eliminate the gender hierarchy and the idea that, physiologically, women must always be oppressed.

Liberal feminists claim that women are continually regarded as less intellectually and physically capable than men. In addition, the inferior intellectual role of women usually happens in school, the labor market, forums, and so on. According to Zoonen (1992), liberal feminists deem men and women as physically identical, with identical fulfillment-goals in life. Women should have the same rights as men, who have access to and recognition in the public, technology, and political fields. The reason why women seem to be behind in technology production and understanding is because they are sometimes reticent to become involved in technology. It is essential for women to retain a positive attitude and skills to obtain an equal position with men in producing and consuming technologies. As Friedan (1990) argues, some educated American women settle for being housewives, and this is the result of patriarchal constructs. It is easy to see this in the commercial advertisements considered earlier; no matter the manner of advertisement, women are usually portrayed as housewives, secretaries, and so on. Liberal feminists claim that women should emancipate themselves from the household, and, thereby, will find out that they actually have a lot of energy and time which could be spent outside the family and to develop themselves. It is also important for women to find a balance between career and family; it is an arduous fight, and society should provide more opportunities for women.

Both the government and non-profit organizations are trying to eliminate stereotypical gender roles and promote altering the portrayal of females in advertising. For instance, the Federal Communication Commission pays a lot of attention to eliminating stereotypical gender roles by making policies and regulations. The Media Education Foundation is another organization that tries to promote better positions for women in our society. There is a video called "Killing Us Softly 4," produced by Jean Kilbourne, which describes advertising's image of women. The movie emphasizes that women are treated as objects in our society rather than as human beings, as 
women must always be positioned as both obscure and materialistic. Thus, this video considers and communicates how women are seen in our society and tries to arouse people's awareness to gender stereotypes.

Technology needs women to participate; if the technology field doesn't fully include women, it cannot be regarded as an integrated field. Women comprise nearly half of all human beings and directly affect both the development of men and of society. As Marx, in a letter to Ludwig Kugelmann in the year of 1868, notes, people who are familiar with history all know that there is no great social revolution without women's effort. Men should realize the contribution that women make to our society; an improved position of women in technology could completely change men's traditional values and thought in order to achieve the accord and development between men and women. Men also have to support women in their participation in the field of technology, and women should try to improve self-quality. To emancipate women in the technology field is not to exterminate women's femininity, to eliminate gender differences and become identical to men; women should, however, try to reduce some negative views of the women's emancipation movements and realize the importance of cooperation with men.

There are a few scholars who have opposite opinions about the relationship between women and information technology. Cantor (1998) argues that men and women were already on the way to being portrayed equally in prime-time television commercials compared with 15 years earlier. He believes that males and females are almost treated as if they are of equal importance in the context of information technology. However, I believe that, even though males and females might be depicted in equal numbers of advertisements, their levels of employment and their roles still differ; men are typically portrayed as holding high-status occupations, while women are housewives or secretaries. In addition, Fountain (2000) has a different opinion about masculine representations in information technology. He argues that information technology provides a lot of opportunities for women to become self-realized and gain liberty. He thinks that, once women are represented strongly in information-technology fields, all society will benefit from a closer relationship with information technology. He believes that new information technology or communication technology will be designed for females, but reality doesn't jive with his claims. Conversely, many researchers argue that information technology continually subverts women's confidence to dominate it and also reinforces women's attachments to men.

\section{Conclusion}

In conclusion, women usually are portrayed in a negative, stereotyped manner and as passive users of information technology. Mass media is an essential component of our society; however, it constantly tries to consolidate the concept of masculinity. As Engels notes, women's emancipation is only being possible when women are able to participate in production and when household work only occupies part of their time. Changing the system of patriarchy is essential. This system leads to an unequal relationship between men and women. In the patriarchal society, the male dominant group's racism, hierarchy, and sexism inevitably control social policy and ideological bias. In order to break the system of patriarchy, women should strive to participate in the field of technology and the field of technology should strive to absorb women's experiences. Even though information technology has developed continuously, the traditional gender hierarchy is still rooted deeply in our society. Information technology has a huge impact on our society; yet, it does not work towards the liberation of women. It is quite crucial for women to be aware of this issue. In addition, building confidence and eliminating stereotypes will help women gain more access to technology and become more involved in production, rather than as simply passive users. As Zoonen (2001) says, the most necessary step to diminish the unequal relationship between men and women is to change deeply-rooted social values and cultural mores. It is important to research changes in gender roles in the future by using information technology and also to study whether information technology can become emancipatory for women. 


\section{ICMETM 2015}

\section{References}

1. Ferguson, M. Forever Feminine: Women's Manazinesand Cult of Femininity. Exeter, NH: Heinemann, 1983.

2. Robbie, A. Feminism and Youth Culture. Basubgstoke: Macmillan, 1991: P91.

3. Zoonen, Liesbet Van, Feminist Media Studies, Taipei: Yuan-Liou Publicshing, 2001, Co.:1540 